\title{
SAND: An Additive for Stabilzation of Swelling Clay Soils
}

\author{
Bahia Louafi ${ }^{1}$, Ramdane Bahar ${ }^{2}$ \\ ${ }^{1}$ Laboratory Built in Environnement (LBE), Faculty of Civil Engineering USTHB, Algiers, Algeria \\ ${ }^{2}$ Faculty of Civil Engineering USTHB, Algiers, Algeria \\ Email: bahialouafi@yahoo.fr, R_bahar@yahoo.fr
}

Received March 21, 2012; revised April 24, 2012; accepted June 5, 2012

\begin{abstract}
An experimental program carried out in this study seeks to understand the physical mechanisms of stabilization of an expansive soil by adding an inert material (sand) at various forms; mixing and intercalation layers of sand. The first aim of the study is to analyze the effect of stabilization on the variation of soil consistency. The results show a marked improvement in soil consistency. Then a study of the effect of the additives on the variation of the swelling in order to solve the lifting structures caused by this phenomenon is carried out. It can be seen that the addition of sand is capable of reducing the swelling action. We complete the study using an ultrasonic device, measuring the propagation velocities of ultrasonic pulse through the tested clay samples. This shows a change occurring in the porosity of the clay when sand is added to it. As a result some interesting conclusions concerning the expansive soil-material amendment are drawn.
\end{abstract}

Keywords: Clay Soils; Bentonite; Sand; Swell; Stabilization

\section{Introduction}

Expansive soils are those which show volumetric changes in response to change their moisture content.

Such soils exhibit alternating cycles of swelling shrinkage, resulting in often substantial damage on civil engineering constructions. This phenomenon of change in volume also depends on a large part of the mineralogical nature of materials that make up the soils and their proportion. The devastating effect of swelling is well established. It affects all types of structures. In Algeria, several cases of disorders very prejudicial, related to swelling, were announced on works in several areas: the oil refinery of In Amenas at the south-east of the country, the hospital of Sidi Chahmi [1,2], the hospital of N'Gaous (Batna), the railway line Ramdane Djamel (Jijel), and the brickyard of Mers El Kébir located at the North-West of the country aproximity of the town of Oran, university of Laghouat [3], the brickyard of Mers El Kébir (Oran), the grouping of Tlemcen-Mansourah, the brickyard of El Achour in Algiers.

This phenomenon is currently one of the first concerns for the specialists on soil mechanics, particularly those faced with problems of expansive soil-structure interaction in semi-arid, arid and hyper arid areas where soils are generally in a state far from saturation. These areas occupy almost a third of the earth's surface. Several studies both in situ and in the laboratory on intact or remolded soil samples were carried out to understand the phenomenon of swelling. However its complexity made it difficult to reach rational solutions to solve it.

Many empirical relations were proposed to characterize the expansibility and the pressure of swelling during its hydration. These relations express swelling on the basis of some characteristic of the ground which is in theory simple to determine in laboratory [4-7]. Such many studies were interested in the factors intervening in swelling [8-14]. Others are leaning on this geotechnical problem in order to release from the solutions being able to minimize or inhibit the pressures developed during the expansion of these clays. These solutions are currently classified among the techniques of stabilization.

There are many techniques for soil stabilization and the choice from one of these techniques depends on several parameters which are economic, practical and environmental. Among these techniques, there are chemical stabilization, thermal stabilization, stabilization by additives such as lime and cement.

Some research works have shown that the addition of inert materials to swelling soil can be a method of stabilizing these soils; [8,15-23]. These works led to consider that the addition of inert materials is a promising technique for stabilizing such soils. Indeed, on the behavior of an amended soil, there are still many open questions that need to be answered. In this work, we study the effect of the performance of an addition of sand on the swelling characteristics of a soil that exhibits swelling. Attempts to analyze the change occurring in the structure of the treated soil, the evolution of the porosity of clay-sand mixtures is analyzed by the study of the ultra- 
sonic velocities measured across the different samples tested.

\section{Materials Used in Tests}

\subsection{Expansive Soil}

It is purely artificial soil clay known as bentonite, from the region of M'zila in the north east of the city of Mostghanem. This material is untreated, gray and comes in the form of finely ground powder. Its average chemical composition is given in Table 1.

Its granulometric curve presented in Figure 1 shows that almost all of the bentonite material passes through a sieve of $80 \mu \mathrm{m}$ and $65 \%$ of the elements are less than 2 $\mu \mathrm{m}$.

The physical characteristics of the bentonite are grouped in Table 2.

\subsection{The Additive}

For the stabilization of expansive soil, beach sand of gray color was used from the area of Zemmouri located in the east of Algiers. Its granulometric curve (Figure 1) shows relatively medium sand, poorly graded and tight. To achieve the bentonite-sand mixtures, three size fractions were extracted from the sand.

First fraction represents fine sand, $0.1 \mathrm{~mm}<\mathrm{d}<0.2$ $\mathrm{mm}$.

Table 1. Chemical composition of bentonite.

\begin{tabular}{cc}
\hline $\mathrm{SiO}_{2}(\%)$ & 58 \\
\hline $\mathrm{Al}_{2} \mathrm{O}_{3}(\%)$ & 19 \\
$\mathrm{MgO}(\%)$ & 1 \\
$\mathrm{Fe}_{2} \mathrm{O}_{3}(\%)$ & 3 \\
$\mathrm{CaO}(\%)$ & 2 \\
Sodium, as $\mathrm{Na}_{2} \mathrm{O}_{3}(\%)$ & 4 \\
Loss on ignition (\%) & 13 \\
\hline
\end{tabular}

Table 2. Physical characteristics of bentonite.

\begin{tabular}{cc}
\hline Property & Value \\
\hline $\begin{array}{c}\text { Specific gravity } \\
\text { Consistency properties }\end{array}$ & 2.6 \\
Liquid limit (\%) & 187 \\
Plastic limit (\%) & 47 \\
Plasticity index $(\%)$ & 140 \\
Optimum moisture content $(\mathrm{OMC})(\%)$ & 25 \\
Maximum dry unit weight $\left(\gamma_{\mathrm{dmax}}\right)\left(\mathrm{kN} / \mathrm{m}^{3}\right)$ & 1.6 \\
\hline
\end{tabular}

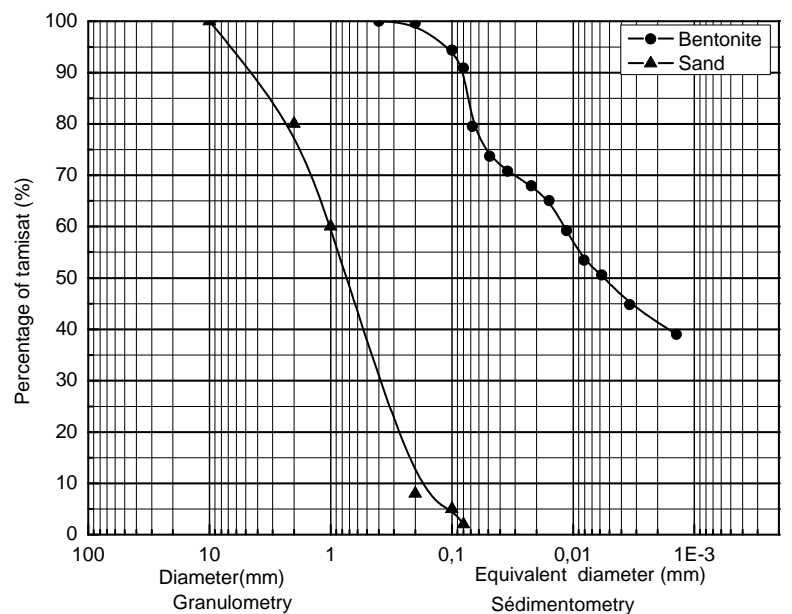

Figure 1. Curve of grain size distribution.

Second fraction represents a medium sand, $0.2 \mathrm{~mm}<\mathrm{d}$ $<0.4 \mathrm{~mm}$.

Third fraction represents a coarse sand, $0.4 \mathrm{~mm}<\mathrm{d}<$ $2.0 \mathrm{~mm}$

\section{Tests Performed and Methods Adopted}

To investigate the physical mechanisms and effects of the stabilization of expansive soil by adding sand as an inert additive in the quantitative aspect, we followed an experimental program based on standard geotechnical tests. The study is primarily focused on the effect of the size of sand grains and the shape of the addition and, secondly of the interaction that occurs between the swelling soil and the material amendment. The study is carried out with respect to the following areas.

\subsection{Consistency Limits}

A series of tests was carried out to study the evolution of the limits of consistency using different assays of sand to point out the influence of the stabilizer on expansive clay soil consistency. To do this, we determine these limits by using distilled water for sand-bentonite mixtures dosed at $10 \%, 20 \%, 30 \%, 40 \%, 50 \%, 60 \%$ and $70 \%$ sand by weight of bentonite.

\subsection{Swelling Tests}

\subsubsection{Effect of Grain Size of Added Sand}

In this study of the size effect, an experimental program was carried out with three sets of free swell tests using in each series a granulometric fraction of the sand used.

For the three series of tests, the same dry density of 1.5 $\mathrm{g} / \mathrm{cm}^{3}$ and the same water content equal to the optimum water content $(26 \%)$ have been fixed. Swell were determinated for untreated bentonite and treated bentonite with varying sand content $(10 \%, 20 \%, 30 \%, 40 \%, 50 \%$, $60 \%$ and $70 \%$ ). The samples were prepared at the ambi- 
ent temperature by manual mixing and were statically compacted directly in the oedometric cell in the three layers, each layers $5 \mathrm{~mm}$, to ensure uniform dry density, using a hand press. Heave was allowed under a seating surcharge of $3 \mathrm{kPa}$ by free inundation or by allowing water continuously into the soil specimen. After final heave $(\Delta \mathrm{H})$ was attained, the sample was compressed under increment vertical loads till initial thickness was attained.

\subsubsection{Effect of the Adding}

In this section we study the possibility to introduce the sand under non-conventional forms. We study the efficiency of using layers of sand, we tested two possible distributions. A sample of bentonite where sand layer is above (dir1), and another sample where sand layer is in the middle (dir2). These two distributions are studied for three percentages of sand: $10 \%, 20 \%$ and $50 \%$.

The method of sample preparation was chosen so as to avoid compacting layer by layer to do not disturb and over compact the lower layers. The sampling consists of preparing the bentonite layers of different thicknesses by static compaction inside the odometer ring, using a hand press, and then assembles the different layers to form the desired sample. This procedure was adopted in order to respect the selected thickness of the layers. In addition, a dry density and initial water content were maintained constant.

\subsection{Ultrasonic Tests}

The purpose of this investigation is to measure the porosity of clay-sand mixtures through the propagation velocity of ultrasonic pulses. We will try to reach some pulse characteristics linking sample volume change to variations of the ultrasonic pulse speed [24].

The tests begin with the calibration of the analyzer in measuring the speed of wave transmission through the rod calibration [25]. Then we measure the velocity of an ultrasonic wave train, which runs through the soil samples tested. To ensure a good sound wave transmission in the body of the specimen and before adjusting the measurement system, we apply thin layers of fat on both sides of contact transducers (transmitter and receiver). On the screen of the analyzer are shown the time or the transit speed of the wave, depending on the configuration of the analyzer

\section{Discussions of Test Results}

\subsection{Evolution of Consistency Limits}

Figures 2 and 3 illustrate the variation of liquid limit and plasticity index based on the percentage of sand for the two fractions of sand used. The results obtained show that the addition of sand to bentonite has a direct influence

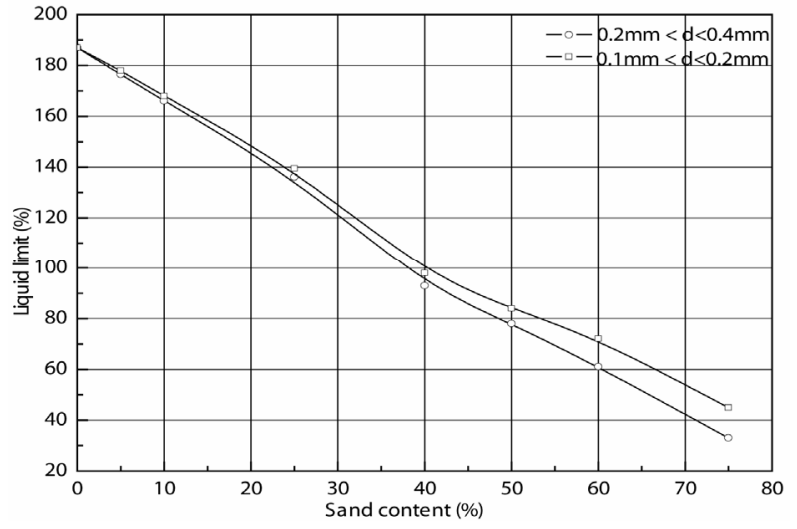

Figure 2. Variation of liquid limit.

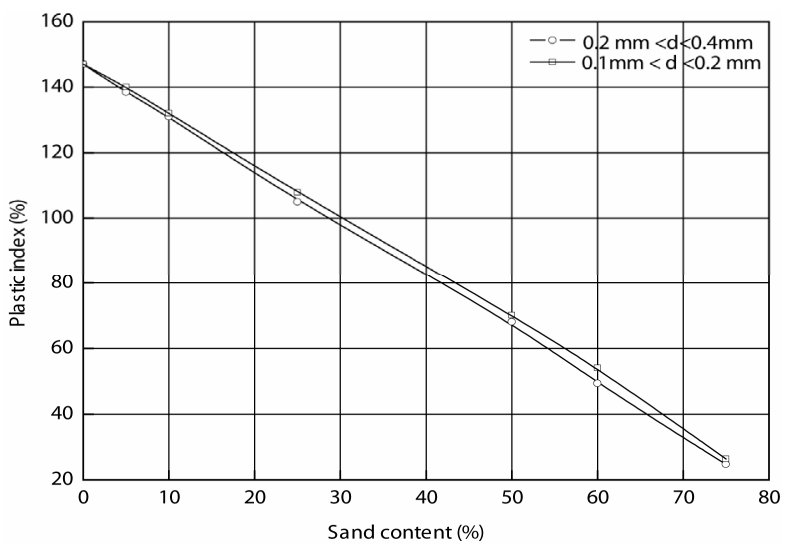

Figure 3. Variation of plastic index.

on the liquid limit and plasticity index, it is observed for both fractions used that lower values of liquid limit and plasticity index are obtained with increasing the amount of sand in the mixtures [26]. This is explained by the decrease in content of fines that contribute to plasticity. Thus the number of bonds between the clay particles is reduced with increased sand-clay particle (sand-clay) bonds or sand-sand particle bonds

The observation of the variation of plasticity (liquid limit and plasticity index) for the two granulometric fractions of sand showed an influence of the granularity of the sand added. This may be due to the total specific surface area of water adsorption of the sample which depends on the size of grains of sand. This specific surface is more important when the sand particles are finer allowing mixtures to absorb water in greater quantities and provide a relatively greater plasticity

\subsection{Swelling}

\subsubsection{Variation of Potential and Swelling Pressure as a Function of Percentage and the Granularity of the Sand}

Curves of Figure 4 show that the potential and swelling 


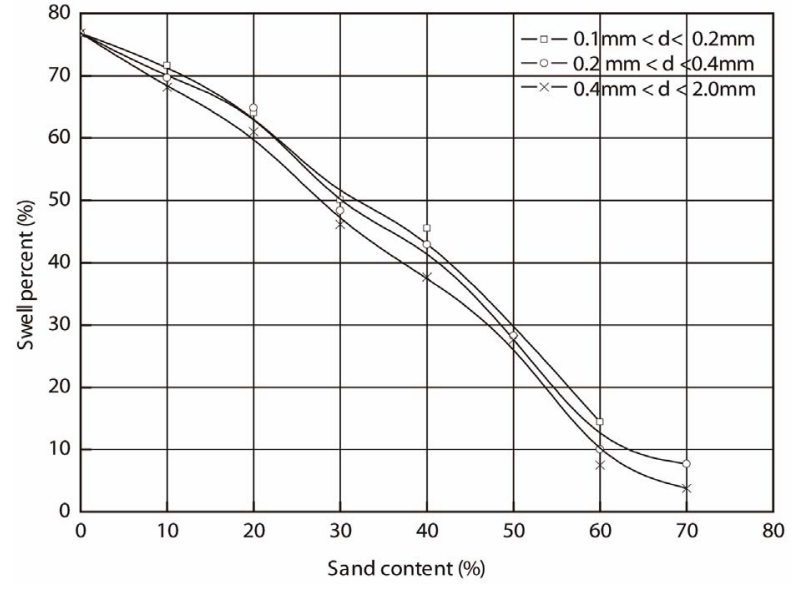

(a)

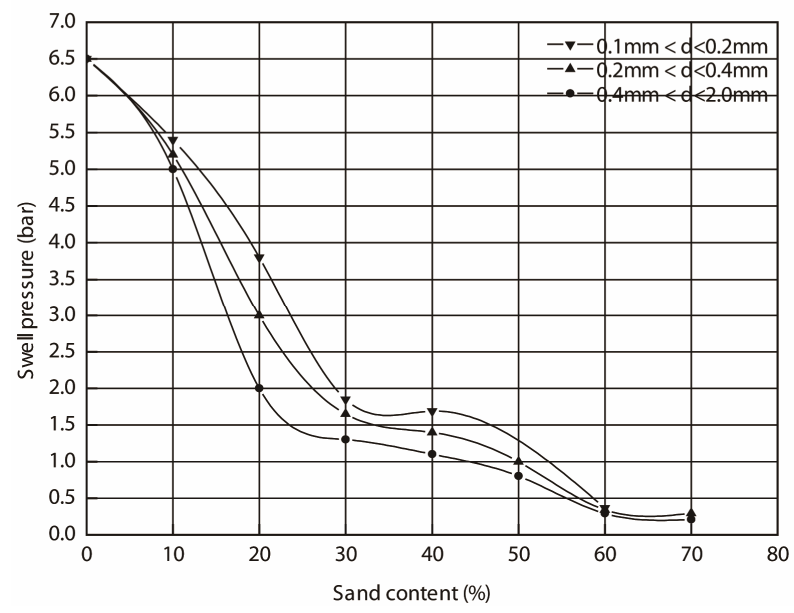

(b)

Figure 4. Variation of swelling potential and swelling pressure with sand content.

pressure of mixed bentonite decrease with increasing the percentage of sand added. We show that at low sand content the reduction rate exceeds the percentage of sand added. This reduction appears to be larger for a given percentage of sand particles when forming the sand fraction is coarse. This difference expresses the effect of the granularity of the sand on the swelling. These results given above can be interpreted by the fact that the clay content decreases by adding mixtures of sand, which is normally inert material. Indeed a greater sand content mixture reduces the amplitude and the swelling pressure; this is on one hand. On the other hand much of this swelling is absorbed by the voids between sand grains. When the fraction of sand is coarser, these voids become larger resulting in a decrease of swelling amplitude. Accordingly, there is a reduction of the potential and swelling pressure developed by the swelling soil. It could also be that with the particle size, the larger effects of gravity contribute to the reduction of swelling of the mixtures.
This steric effect would prevent or interfere by its inertia the deformation of expansive soil and results in a potential and swelling pressure lower for larger particles. This result has to be confirmed for larger particle diameters

\subsubsection{Effect of the Shape of the Addition on the Rate of Swelling}

Examination of the Figure 5 illustrates the variation in the rate of swelling based on the percentage of sand used for the three configurations (sand layer above, sand layer in the middle, mixing procedure). It shows the influence of the shape of the addition in the reduction of swelling clay. We note that for small amounts of sand added the gap between curves corresponding to the three techniques is very low. The reduction of swelling for these levels is due to the decrease in the clay fraction, which explains that the effect of the shape of the addition is negligible. In the contrary, to high percentages of sand, the gap between the curves becomes important and particularly between the curves corresponding to the addition of layer sand and by mixing procedure. Mixing allows sand particles to distribute in the clay and consequently play their full role in reducing the rate of swelling (absorption of swelling in existing voids, prevention by inertia and reduction bonds between clay particles by interposition of the grains of sand). Whereas in the technique of sand added by layers a certain amount of sand remaining on the sidelines and that has been observed on samples tested after swelling. In this case the sand plays only one role, that is to prevent from swelling by inertia and why not reduces the fines content.

\subsubsection{Swelling Kinetics}

The curves of Figures 6 and 7 representing the temporal evolution of the swelling potential, show the same shape for the various concentrations of sand, and also for the three fractions studied and the different shapes of the addition. These curves show a higher swelling potential

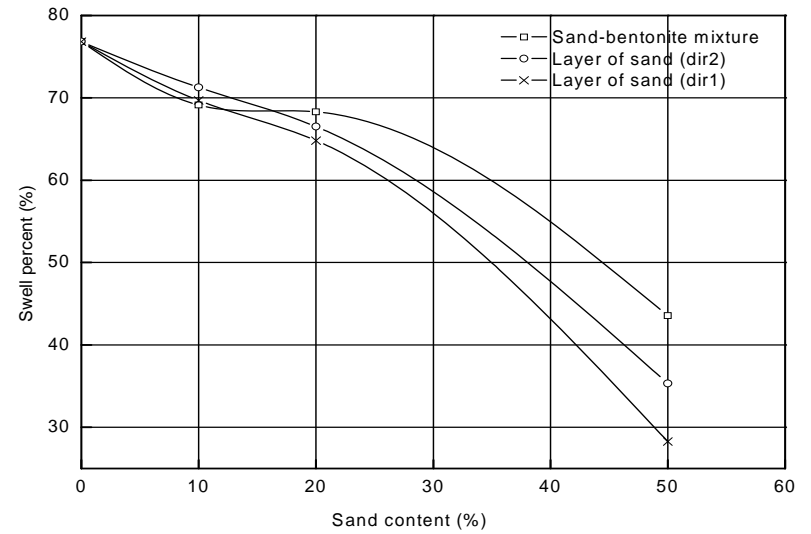

Figure 5. Variation of swelling potential for three configurations with sand added. 


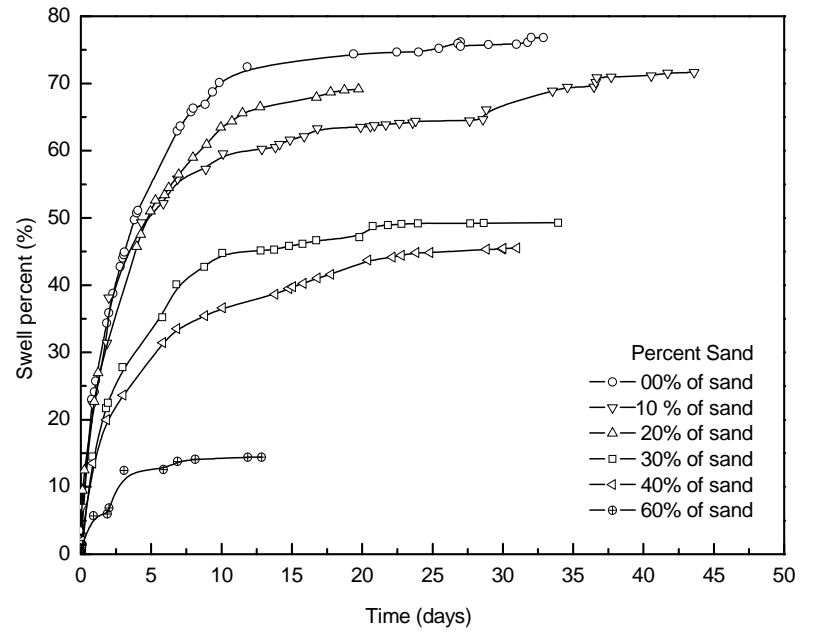

(a)

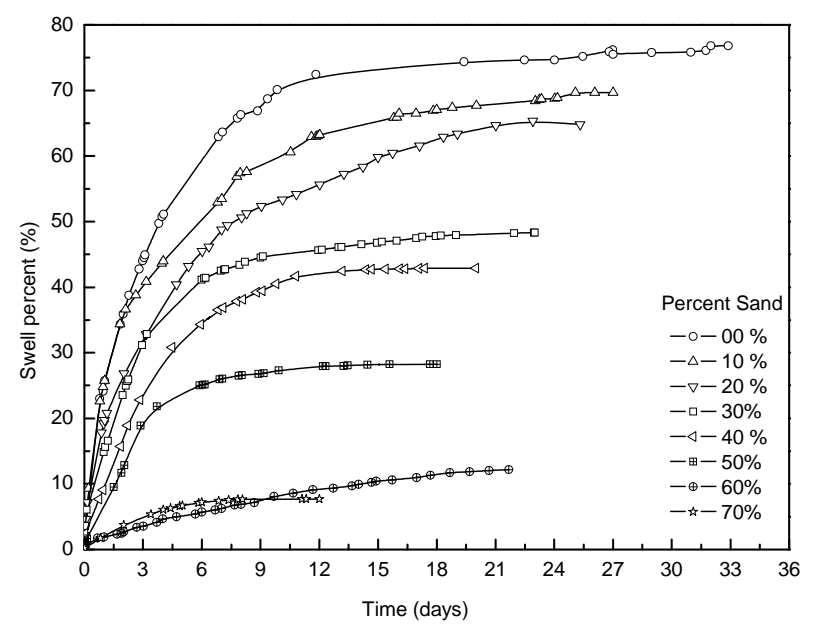

(b)

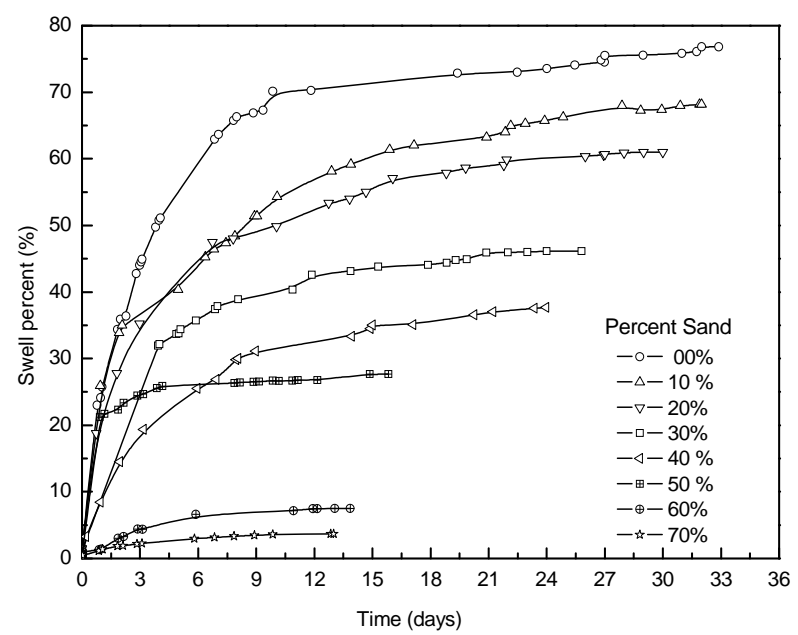

(c)

Figure 6. (a) Swelling kinetics fraction $0.1 \mathrm{~mm}<\mathrm{d}<0.2 \mathrm{~mm}$; (b) Swelling kinetics fraction $0.2 \mathrm{~mm}<$ d $<0.4 \mathrm{~mm}$; (c) Swelling kinetics fraction $0.4 \mathrm{~mm}<\mathrm{d}<2.0 \mathrm{~mm}$.

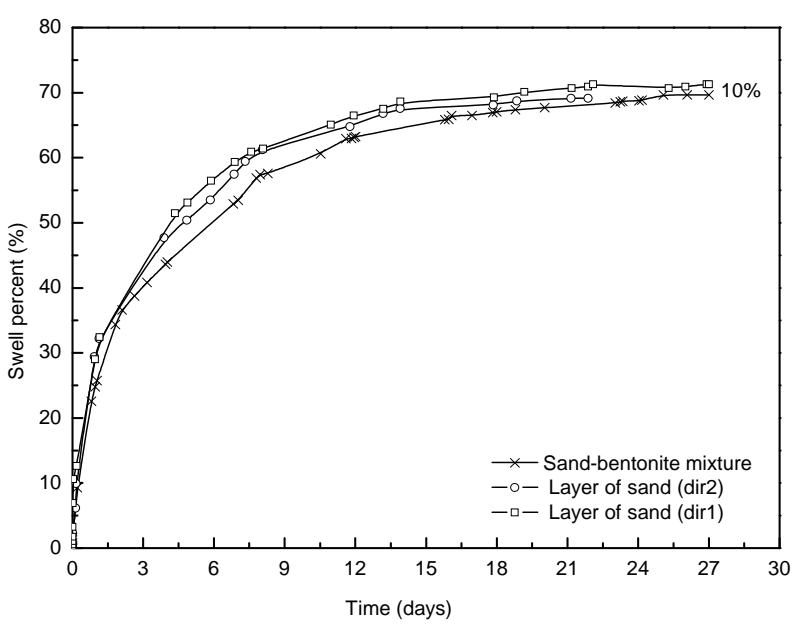

(a)

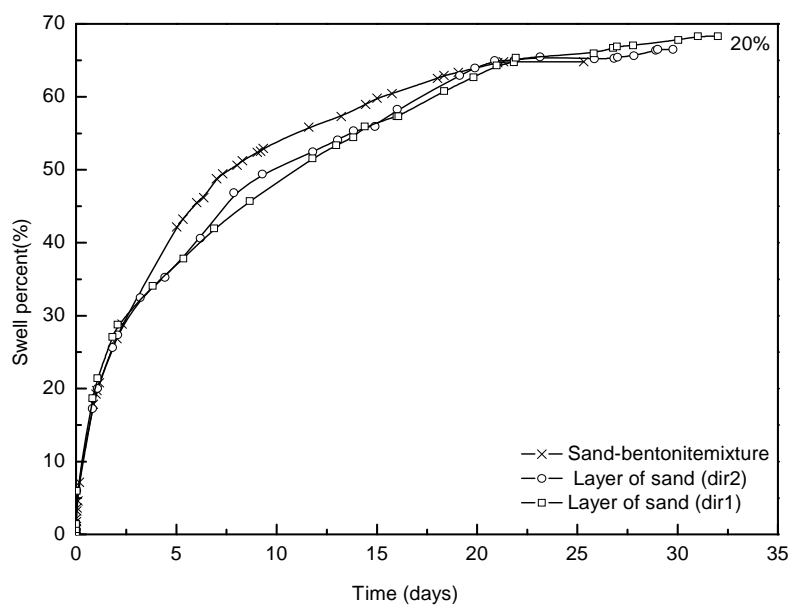

(b)

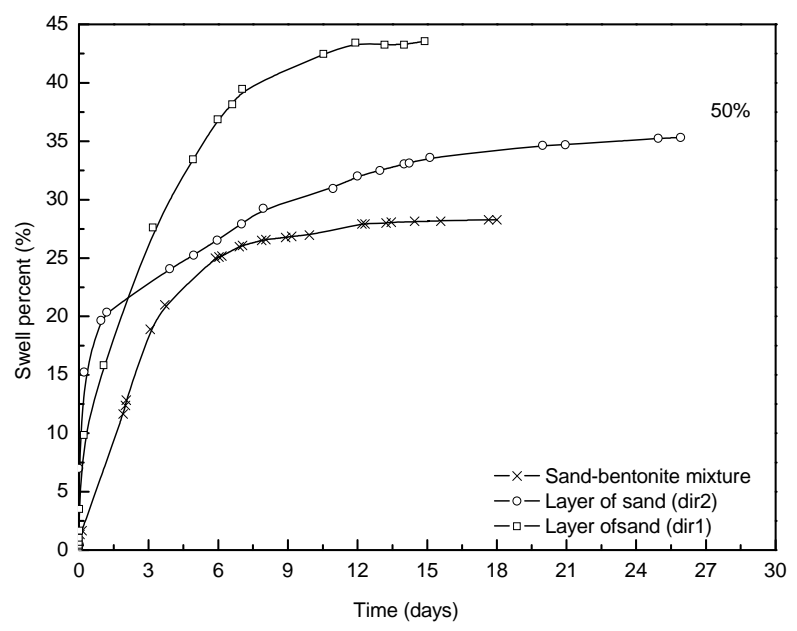

(c)

Figure 7. Evolution over time of potential of sand layers used at $10 \%, 20 \%$ and $50 \%$ sand.

for bentonite alone, which decreases with increasing dosage of sand mixtures. 
On each curve, we distinguish that the evolution of the potential swelling occurs in two stages. Initially the swelling is very fast, it starts when the sample is flooded. This first stage of swelling corresponds to a macroscopic swelling governed primarily by the permeability of the medium and the gradient of suction. In a second stage the swelling is slow and progressive (microscopic swelling) up to the time needed to stabilize. We note that the latter is shortened with increasing sand content mixtures. The second phase of the swelling would be a progressive process of clay minerals and cations adsorbed; this hydration is due to the water available in the pores.

\subsection{Ultrasonic Speed and Content of Sand}

Curve of the Figure 8, one notes the reduction in the propagation velocity ultrasonic with the content of sand of the mixtures and becomes very weak and non perceptible to $50 \%$ of sand. This variation in the decreasing direction expresses the increase in the porosity of the mixtures by sand addition. This result highlights the reduction in the density of clay and makes it possible to confirm the evolution in the direction decreasing of the swelling of clay by sand addition.

\section{Conclusions}

Based on the study undertaken thus far, it can be concluded that:

1) The addition of sand reduces all parameters of consistency. The reduction is slightly affected by the granularity of the sand. Plasticity is relatively more important when the sand added is finer.

2) The results obtained showed the effectiveness of sand in the stabilization of expansive soils. The evolution of swelling with the sand content is similar for all samples tested regardless of the granularity of the sand fraction added or form of its addition.

3) Moreover, the introduction of sand as layers distributed into two different configurations (layer on top of

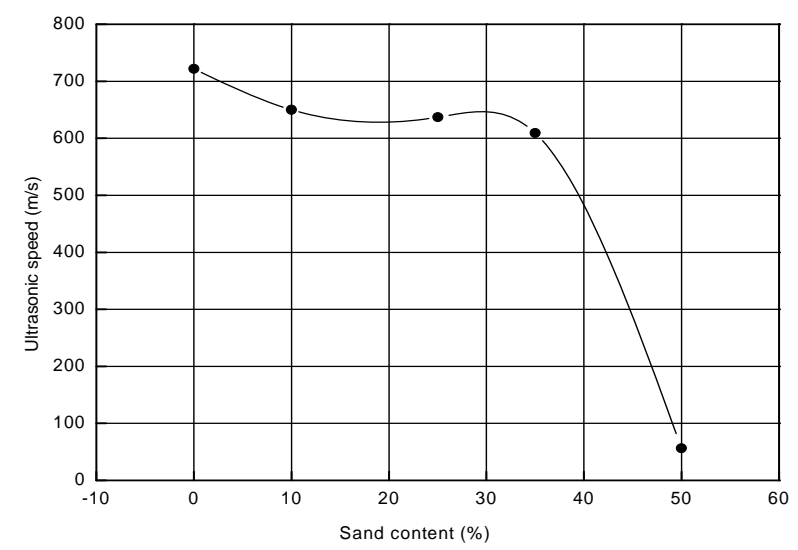

Figure 8. Variation of ultrasonic speed with sand added. sample and layer in the middle) showed the effectiveness of these layers in reducing swelling. It was found that the most efficient distribution in reducing swelling is that of layers of sand placed between two layers of clay compared to the sand layer placed on top of sample. The latter provides a single contact surface only between the two materials used.

4) The technique of mixing can provide a better distribution of clay particles in the voids created in the mixture and thus allows a reduction in the number of bonds between the clay particles by an increase in typical bonds between sand grains and clay particles .Consequently the volume changes are less important.

5) In addition to the effects of size and shape of the addition is not noticeable for low levels of sand, confirming that the reduction of swelling for these levels is the result of the decrease in the clay fraction.

6) Finally, the overall analysis of the porosity by ultrasonic pulse propagation showed an increase in the volume of voids with increasing sand content. This modification in the structure of bentonite treated by sand, made it possible to find a response to the appeal of the reduction in the swelling of clay by sand addition. It is come out from this study that the reduction of swelling is the result also of the reduction in the clean density of clay in the mixture.

\section{REFERENCES}

[1] Z. Derriche and M. Kebaili, "Prévision du Gonflement des Argiles d'In Amenas," Bulletin des Laboratoires des Ponts et Chaussées, 1998, pp. 15-23.

[2] A. Hachichi and J. M. Fleureau, "Caractérisation et Stabilisation de Quelques Sols Gonflants d'Algérie," Revue Française de Géotechnique, No. 86, 1999, pp. 37-51.

[3] M. Lamara and A. Merah, "Analyse d'un Cas Pathologique de Gonflement de Sol (Université de Laghouat)," Journée d'Études sur les Sols Gonflants, Tlemcen, 27-28 Octobre 2002, pp. 101-110.

[4] H. B. Seed, et al., "Prediction of Swelling Potential for Compacted Clays," Journal of the Soil Mechanics and Foundations Division, Vol. 88, No. 3, 1962, pp. 53-87.

[5] W. G. Holtz and H. J. Gibbs, "Engineering Properties of Expansive Soils," Transactions of ASCE, Vol. 121, 1956, pp. 641-679.

[6] Ranganatham and B. Satyanaryana, "A Rational Method of Predicting Swelling Potential of Compacted Expansive Clays," Proceedings of the 6th International Conference on Soil Mechanics and Foundation Engineering, Montréal, 1965, pp. 92-96.

[7] G. Didier, "Gonflement Cristallin et Macroscopique des Montmorillonites, sa Prévision," Doctor Thesis, University Claude Bernard, Lyon, 1972.

[8] M. A. El-Sohby and E. A. Rabba, "Some Factors Affecting Swelling of Clayey Soils," Geotechnic Engineering Journal, Vol. 12, 1981, pp. 19-39. 
[9] F. H. Chen, "Foundation on Expansive Soil, Developments in Geotechnical Engineering," Elsevier Publishing Co., Amsterdam, 1988.

[10] H. Komine and N. Ogata, "Experimental Study on Swelling Characteristics of Compacted Bentonite," Canadian Jour- nal of Geotechnique, Vol. 33, 1994, pp. 11-22. doi:10.1139/t96-021

[11] A. S. Rao, R. Phanikumar and R. S. Sharma, "Prediction of Swelling Characteristics of Remolded and Compacted Expansive Soils Using Free Swell Index," Quarterly Journal of Engineering Geology and Hydrogeology, Vol. 37, 2004, pp. 217-226. doi:10.1144/1470-9236/03-052

[12] A. Djedid and N. Ouadah, "Paramètres d'État et Gonflement des Sols Argileux, Exemple de la Teneur en Eau et de la Densité Sèche Initiale," Colloque International Sols Non Saturés et Environnement, Tlemcen, 27-28 Octobre 2009, pp. 436-444.

[13] P. Mouroux, "Contribution à l'Étude des Problèmes de Retrait et de Gonflement des Sols," Thése de Doctorat, l'Université de Grenoble, Grenoble, 1969.

[14] Z. Derriche, "Analyse du Mécanisme de Gonflement des Argiles Compactes," Algérie Equipement, No. 17, 1995.

[15] F. Kaoua, Z. Derriche and N. Laradi, "Contribution à l'Étude de la Stabilisation des Sols Gonflants par Ajout de Sable," Algérie Equipement, Revue Technique de l'Ecole National des Travaux Publiques, No. 15, 1994, pp. 12-15.

[16] L. Bengraa , A. Hachichi, S. A. Bourokba and A. Benaissa, "Etude de la Stabilisation des Argiles Gonflantes par Ajout de Sable de Carrière," University of Tlemcen, Tlemcen, 2005, pp. 101-112.

[17] M. Lamara, M. K. Gueddouda, A. Benaissa and A. Hachichi, "Stabilisation des Sols Gonflants par Ajout de Sable de Dune,"University of Tlemcen, Tlemcen, 2005, pp. 129-139.

[18] B. Louafi, "Contribution to the Study of the Stabilization of an Expansive by Sand Addition," Doctor Thesis, University of Sciences and Technology Houari Boumedienne,
Algiers, 1997.

[19] B. Louafi and Z. Derriche, "Effet de la Granularité et de la Forme des Grains de Sable sur les Caractéristiques des Argiles Compactées," In: P. G. Marinos, G. C. Koukis, G. C. Tsiambaos and G. C. Stournaras, Eds., Engineering Geology and the Environment, Balkema, Rotterdam, 1997, pp. 85-90.

[20] B. Louafi and R. Bahar, "Evolution des Caractéristiques Géotechniques d'une Argile Purement Gonflante par Additifs à Aspect Inerte," International Conference on Geotechnical Engineering, Hammamet, 25-27 Octobre 2010, pp. 287-294.

[21] B. Louafi and R. Bahar, "Etude en Laboratoire de l'Effet de l'Apport d'un Matériau Inerte sur les Caractéristiques de Gonflement d'une Marne Argileuse," 10th Edition of International Congrés of Mechanics, Ecole Nationale des Sciences Appliqués, Oujda, 19-22 April 2011, pp. 293295.

[22] B. Satyanaryana, "Behaviour of Expansive Soil Treated or Cushioned with Sand," 3rd International Conférence on Expansive Soils, Haifa, 1973, pp. 308-316.

[23] Moussa, et al., "Effect of Sand Cushion on Swelling and Swelling Pressure of Expansive Silty Clay," Proceeding of the 11th International Conférence on Soil Mechanics and Foundation Engineering, San Francisco, 1985, pp. 1023-1026.

[24] M. Goueygou, "Relationship between Porosity, Permeability and Ultrasonic Parameters in Sound and Damage Mortar," International Symposium Non-Destructive Testing in Civil Engineering, Berlin, 16-19 September 2003.

[25] V. M. Malhotra and N. J Carino, "Handbook on Destructive Testing of Concrete," Edition Eyrolles, 2003.

[26] H. A. Alawaji, "Swell and Compressibility Characteristics of Sand-Bentonite Mixtures Inundated with Liquids," Applied Clay Science, Vo1. 5, No. 3-4, 1999, pp. 411430. 